\title{
Glutathione S-transferase enzyme activity and protein expression in patients with recurrent tonsillitis and idiopathic tonsillar hypertrophy
}

\author{
Sedat Aydina, Mehmet Gokhan Demir ${ }^{b}$, Serpil Oguztuzunc , Murat Kilic ${ }^{d}$, Can Yilmaz ${ }^{e}$, Onur Diricanc
}

\begin{abstract}
Objectives. The palatine tonsil is a significant part of the secondary immune system. Tonsillitis and idiopathic tonsillar hypertrophy (ITH) are the most common pathologies of this component. Although there are studies on their pathogenesis, there is insufficient study of the role of antioxidant agents. Glutathione S-transferase (GST) isozymes contribute to the antioxidation reactions in the tissue via the glutathione pathway. The purpose in this study was to reveal the levels of the GST enzyme activity and protein expression of GSTP1 and GSTA1 isozymes in patients with tonsillitis and tonsil hypertrophy, and to investigate their role in the pathogenesis of these diseases.

Materials and Methods. Sixteen patients with recurrent tonsillitis and 5 patients with ITH and were included in the study. Cytosolic extracts were prepared from post-tonsillectomy tissues of both patient groups and GST enzyme activities were measured.

Results. The expression of GSTP1 was found to be significantly higher than GSTA1 in tissue samples of patients with ITH and recurrent tonsillitis $(P<0.001)$. Increased GST activity and GSTP1 isozyme expression were shown in patients with recurrent tonsillitis compared to the idiopathic tonsillar hypertrophy study group. There was a positive correlation between the expressions of GSTP1 $(P=0.040 ; r=0.47)$.

Conclusion. Increased GST activity and GSTP1 isozymes were demonstrated histologically in the pathogenesis of ITH and recurrent tonsillitis. We believe that the data of changes in antioxidant capacity, obtained from studies with more extensive and larger samples, would support our findings.
\end{abstract}

Key words: glutathione S-transferase, GSTA1, GSTP1, idiopathic tonsillar hypertrophy, recurrent tonsillitis

Received: August 5, 2018; Accepted: January 29, 2019; Available online: February 12, 2019

https://doi.org/10.5507/bp.2019.002

(c) 2019 The Authors. This is an open access article licensed under the Creative Commons Attribution License (https://creativecommons.org/licenses/by/4.0/).

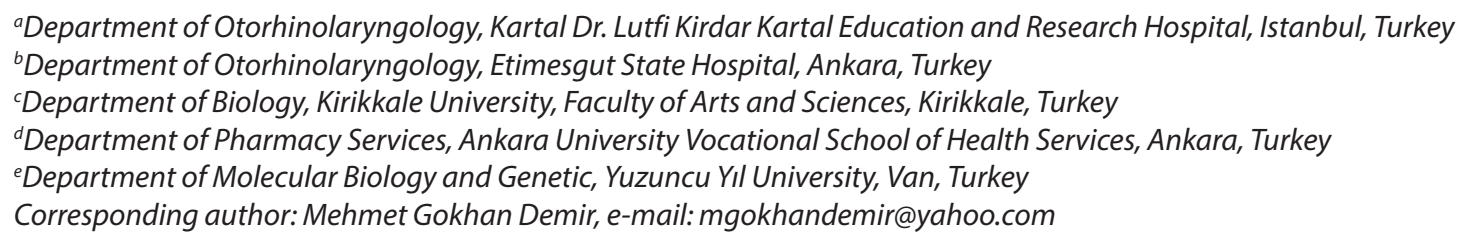

\section{INTRODUCTION}

Palatine tonsils, which are located at the entrance to the gastrointestinal and respiratory tracts and are the first places of exposure of the body to pathogens and antigenicity through inhalation and digestion, are components of the secondary immune system with immunobiological activity $^{1,2}$. As the palatine tonsils have an active role in the immune system, pathologies such as idiopathic tonsillar hypertrophy (ITH) and recurrent tonsillitis (RT) are frequently observed ${ }^{3}$. While both fibrosis and changes at the quantity of the follicles are observed in the extrafollicular tissue in recurrent tonsillitis, idiopathic tonsillar hypertrophy is a pathological condition characterized by lymphoid hyperplasia in the germinal center of the tonsil.

As it is known, free radicals have adverse impacts on overall metabolic activity and the immune defense system. In acute or chronic inflammatory phase, the accumulation and production of these radicals may not be controlled and balanced ${ }^{4}$. With the increase in such products, tissue damage is occurred , and it causes several pathologies such as; atherosclerosis, stroke, nasal polyps, cataract, arthritis, hearing loss, and reperfusion injury ${ }^{5-7}$.

Glutathione which is one of the most significant antioxidant product of the cell, is conjugated to reactive electrophilic species by glutathione S-transferase enzymes (GST). Their role is to detoxify chemicals which are the carcinogenic and toxic to healthy cells ${ }^{7,8}$.

Expression of GSTs increases as a result of the presence of oxidative damage, toxins or temperature changes. Promoters of the GSTs also have own antioxidant elements $^{3}$. For this reason, GSTs are believed to be a component of the adaptive response in tissue damage ${ }^{5-9}$. Both GSH and GSTs are key components of the further metabolism of the oxidative stress products ${ }^{5}$.

GSTs are also responsible for the elimination of the reactive oxygen species that are created in the respiratory chain in mitochondria ${ }^{10}$. Additionally, this protection also can be seen in severely damaged cells which can transform into cancer cells ${ }^{11}$. GSTs polymorphism which was defined previously, was associated to the resistance of the tumor to cancer treatment ${ }^{12}$. The most common subfamily 
of the GSTs in aerobic organisms is the cytosolic GSTs which have role in detoxification reactions of compounds such as electrophilic nitrogen, sulfur and carbon atom ${ }^{3,5}$. Cytosolic GSTs have isozymes such as zeta (GSTZ) mu (GSTM), pi (GSTP), omega (GSTO), sigma (GSTS), theta (GSTT) and alpha (GSTA).

The rationale behind the research is that the composition and activity levels of GST isozymes might be different if ITH and RT were defined as histopathologically different clinical conditions. According to our knowledge, this is the first study which compares ITH and RT by means of GSTP1, GSTA1 expressions in tonsil tissue.

\section{MATERIALS AND METHODS}

\section{Patient selection}

The study included patients who were treated in our clinic between 2008 and 2010 with a diagnosis of idiopathic tonsillar hypertrophy or recurrent tonsillitis. The patients were monitored for 3 years in the RT group and 2 years in the ITH group. The recurrent tonsillitis patient group consisted of 16 (12 male, 4 female) patients and the idiopathic tonsillar hypertrophy group consisted of 5 ( 3 male, 2 female) patients. The ages ranged from 4-15 years old (mean 8.4).

Recurrent tonsillitis was defined as more than 3 episodes a year during a 3-year period, or more than 5 episodes a year during a 2-year period, or more than 7 episodes in 1 year ${ }^{13}$.

Idiopathic tonsillar hypertrophy was defined as tonsillar tissues obstructing $\geq 50 \%$ of oropharynx with marked dysphagia, snoring, difficulty in breathing, and no hypertrophy of the adenoid tissue. Patients with concurrent septum deviation, adenoid hypertrophy, congenital anomalies of the respiratory tract and history of systemic disease were excluded from the study. The patient selection was narrow and the two study groups were small due to exclusion criteria (Children from 4-15 years, had mostly adenoidal hypertrophy together with ITH. Also, the ages ranged from 4-15 years and this range could be narrower because 6-10 years there is physiological involution of the tonsillar tissue and the diagnosis of ITH is less common in older children.) For this reason, twenty-one selected patients underwent tonsillectomy and the tissues were prepared for further examination.

\section{Preparation of cytosolic extracts from tonsillar tissues}

Frozen tissue samples were weighed and dissolved in a 1:5 (weight/volume) precooled, TED buffer solution (containing $10 \mathrm{mM}$ Tris-HCl, pH 7.8, 1 mM EDTA, $1 \mathrm{mM}$ DTT and $100 \mu \mathrm{M}$ PMSF). These tissues were shredded into small pieces by tissue scissors and were transferred to a Teflon-glass homogenizer. The homogenates obtained after about 10 applications in ice for $45 \mathrm{~s}$ were transferred to centrifuge tubes and were centrifuged at $12000 \mathrm{~g}$ for 25 min (Sorvall Legend Micro 21, ThermoFisher Scientific). The obtained supernatant was transferred to an ultracentrifuge tube and was centrifuged at $134000 \mathrm{~g}$ for 50 min (Sorvall MTX 150 Bench Micro-Ultracentrifuge,
ThermoFisher Scientific). The resulting supernatant was divided into aliquots and stored at $-80^{\circ} \mathrm{C}$ to be used later in protein determination, activity assays, SDS-PAGE, and Western blotting. Protein concentrations were measured by the method described by Lowry et al. ${ }^{14}$ using bovine serum albumin as standard.

Total protein concentration measurements of the samples were performed according to the method of Lowry et al. ${ }^{14}$ and the volume and the concentrations of the content of the reaction medium were adjusted for ELISA microplate system. A standard curve was constructed using five different concentrations of Bovine Serum Albumin (0 mg/mL, $0.1 \mathrm{mg} / \mathrm{mL}, 0.25 \mathrm{mg} / \mathrm{mL}, 0.5 \mathrm{mg} / \mathrm{mL}, 1 \mathrm{mg} /$ $\mathrm{mL}, 1.5 \mathrm{mg} / \mathrm{mL}$ ) and the slope of this curve was used in the calculation of protein concentrations in the tonsil samples.

\section{Measurement of GST activities}

GST activities were determined spectrophotometrically as described by Habig et al (1974). This is based on monitoring thioether formation in the reaction medium at $340 \mathrm{~nm}$ using CDNB as substrate ${ }^{15}$. This method has been modified for the ELISA microplate reader system ${ }^{16}$. Each reaction well contained $100 \mathrm{mM}$ potassium phosphate buffer pH 7.4, 1.0 mM GSH, 1.0 mM CDNB, a cytosolic extract containing $0.07-0.036 \mathrm{mg} / \mathrm{mL}$ protein. The reaction mixtures in the micro-wells and their controls were prepared in triplicate and the absorbance values were measured at $20 \mathrm{~s}$ intervals for $10 \mathrm{~min}$ after the addition of the extracts. In addition, two separate concentrations were prepared from these triple sets for each sample; thus, averages of measurements were used from 6 different wells in total. Absorbance values were measured with Bio-Tek ELx808 ELISA Plate Reader system and calculated with KC Junior software. Specific activity values were calculated using the formula:

$$
\left[\frac{\frac{d A}{d t}}{\varepsilon\left(m M^{-}\right)}\right] x D F x\left(\frac{1}{\frac{m g \text { protein }}{m L}}\right)
$$

$\mathrm{dA} / \mathrm{dt}$ represents the rate of enzyme activity in $\mathrm{mOD} / \mathrm{min}$ (change in absorbance per unit time), $\varepsilon$ is the extinction coefficient $\left(9,6 \mathrm{mM}^{-1} \mathrm{~cm}^{-1}\right)$, and DF is the dilution factor.

\section{Measurement of protein concentrations for Western blotting}

Total protein concentrations in cytosols were measured fluorometrically by a Qubit fluorometer with "The Qubit $^{\circledR}$ Protein Assay Kits” commercial kits.

\section{Determination of protein expressions of GSTP1 and GSTA1 isozymes by Western blotting}

A mixture of cytosolic extract containing $50 \mu \mathrm{g}$ of total protein, LDS Sample Buffer, Reducing Agent and deionized water at a final volume of $20 \mu \mathrm{L}$ was prepared for each subject and heated at $70{ }^{\circ} \mathrm{C}$ for $10 \mathrm{~min}$. The samples were loaded onto a NuPAGE 4-12\% $1.0 \mathrm{~mm}$ BisTris Gel (Cat. No. NP0321BOX) and run with 1X MES SDS buffer (Cat. No.NP0002). Gels were transferred using the iBlot Transfer Stack, the iBlot Transfer Stack, 


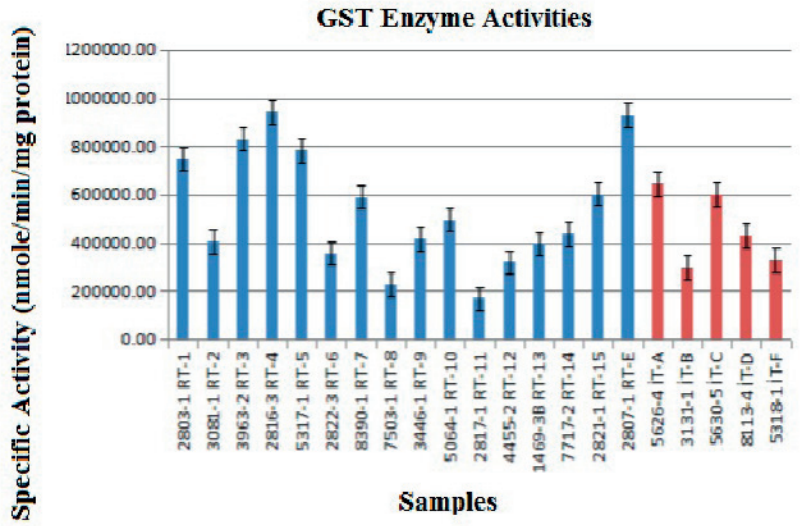

Fig. 1. GST activities were increased in patients with recurrent tonsillitis and idiopathic tonsillar hypertrophy.

*: The protein expression difference between GSTP1 and GSTA1 were examined using the Mann-Whitney U test with 95\% confidence level

PVDF Regular (Cat. No. IB4010-01) on the iBlot Gel Transfer Device at $20 \mathrm{~V}$ for $7 \mathrm{~min}$. Traditional blots were processed according to The iBlot Western Detection Kits protocol. Briefly, the membrane was blocked for $30 \mathrm{~min}$ using the Western Breeze blocking solution, incubated with the GSTP1 and GSTA1 primary antibodies (Santa Cruz Biotechnology, Inc.). at a dilution of 1:1000 for $1 \mathrm{~h}$,

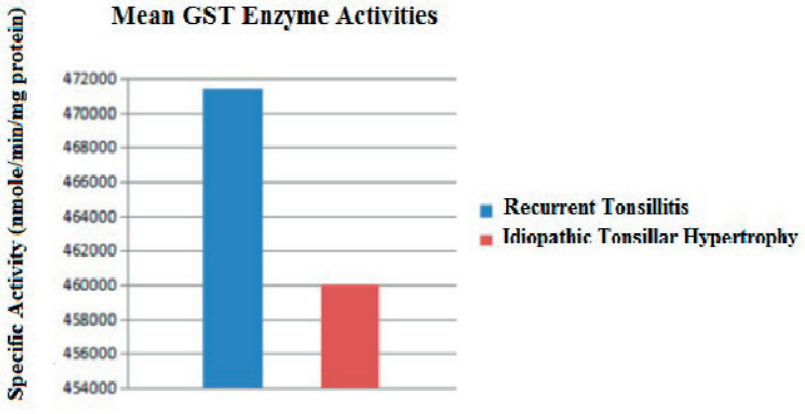

Fig. 2. The distribution of mean GST activity among the groups $(P>0.050)$.

washed, and then incubated for $30 \mathrm{~min}$ with the supplied prediluted secondary antibody before the final washes and exposure to the Western Breeze substrate -Bromo-4chloro-3-indolyl phosphate/nitroblue tetrazolium (BCIP/ NBT). All washes were carried out according to the protocol using the supplied buffers. BCIP/NBT was used to visualize alkaline phosphatase activity in the tissues ${ }^{17}$. The

Table 1. Mean GST enzyme activity levels in study groups.

\begin{tabular}{|c|c|c|c|}
\hline Enzyme & $\mathrm{RT}^{\mathrm{a}}(\mathrm{n}=16)$ & $\operatorname{ITH}^{\mathrm{b}}(\mathrm{n}=5)$ & $\begin{array}{c}\mathrm{R}^{*} \\
P^{* *} \text { value }\end{array}$ \\
\hline GST & $471383.07^{\mathrm{c}} \pm 56293$ & $460011.61 \pm 69908$ & $\begin{array}{c}1.02 \\
0.9671\end{array}$ \\
\hline
\end{tabular}

a: Recurrent tonsillar hypertrophy

b: Idiopathic tonsil hypertrophy

c: Average GST enzyme activity values

*: Ratio of average GST enzyme activity values in patients with recurrent tonsillitis and idiopathic tonsil hypertrophy, \pm std. mean

$* *$ : Differences of enzyme activity between RT and ITH were examined using the Mann-Whitney U test with 95\% confidence level

Table 2. GSTP1 level was statistically higher than GSTA1 level in patients with recurrent tonsillitis and idiopathic tonsillar hypertrophy $(P<0.001)$.

\begin{tabular}{cccc}
\hline & GSTP1 & GSTA1 & $\begin{array}{c}\mathrm{R}^{\mathrm{d}} \\
\left(P^{*} \text { value }\right)\end{array}$ \\
\hline $\mathrm{RT}^{\mathrm{a}}$ & $19081158^{\mathrm{c}} \pm 1284906$ & $3967780 \pm 972298$ & 4.81 \\
$(\mathrm{n}=16)$ & & & $(0.000)$ \\
$\mathrm{ITH}^{\mathrm{b}}$ & $22987399 \pm 1731742$ & $4902719 \pm 1320813$ & 4.69 \\
$(\mathrm{n}=5)$ & 0.83 & 0.81 & $(0.0122)$ \\
$\mathrm{R}^{\mathrm{e}}$ & $(0.1485)$ & $(0.6797)$ & \\
$(P$ value $)$ & & \\
\hline
\end{tabular}

a: Recurrent tonsillar hypertrophy

b: Idiopathic tonsil hypertrophy

c: The average intensity values obtained from the gel imaging system of the resultant membrane bands of western blot analysis, \pm std. mean

d: ratio of GSTP1 and GSTA1 average intensity in patients with Recurrent tonsillar hypertrophy and Idiopathic tonsil hypertrophy

e: ratio of GSTP1 and GSTA1 average intensity between Recurrent tonsillar hypertrophy and Idiopathic tonsil hypertrophy patients 


\section{Expression of GSTP1 in RT and ITH}
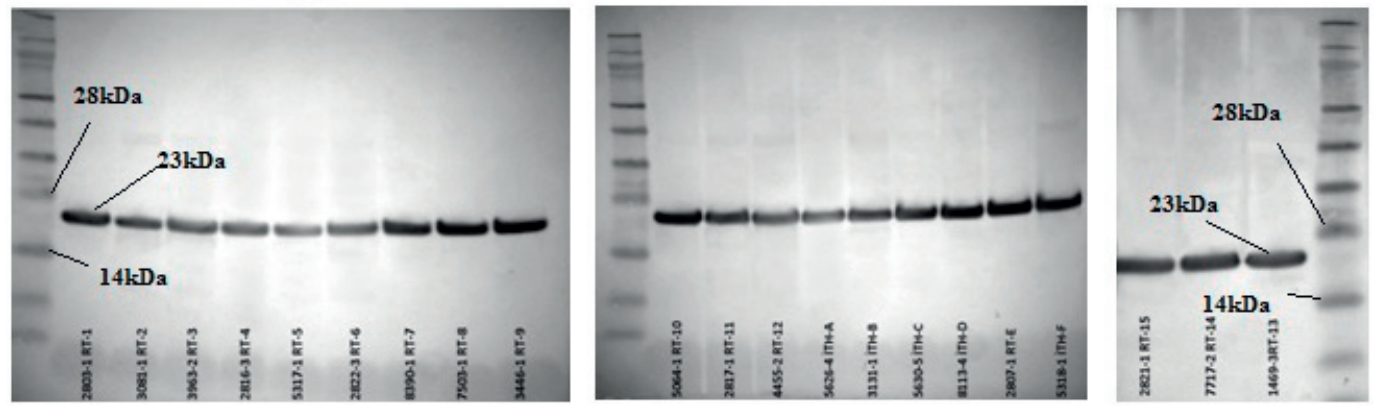

\section{B-Actin (internal control)}
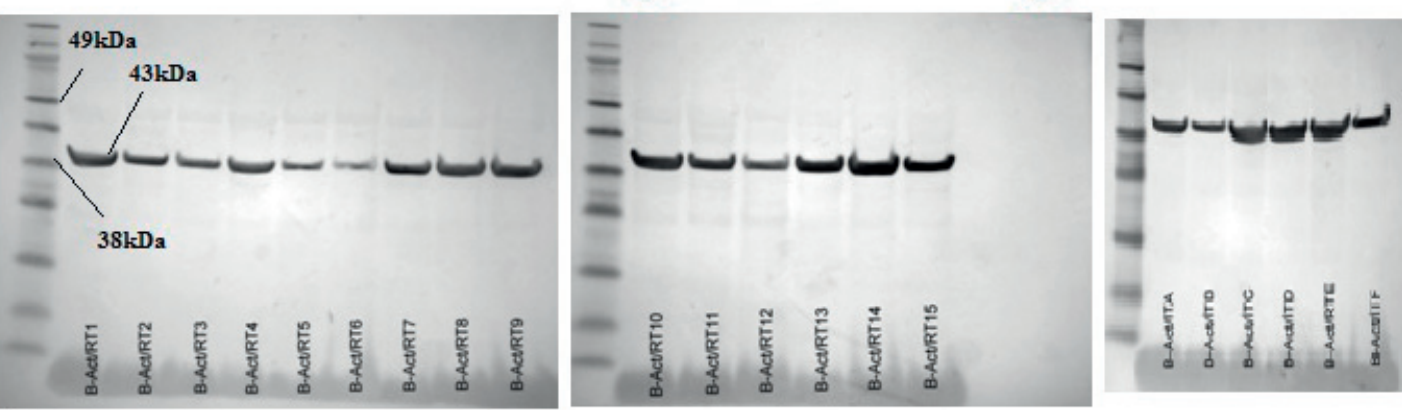

Fig. 3. Immunodetection of GSTP1, B-actin in recurrent tonsillitis and idiopathic tonsillar hypertrophy cytosolic fractions $(\sim 50 \mu \mathrm{g}$ protein $)$.

\section{Expression of GSTA1 in RT and ITH}
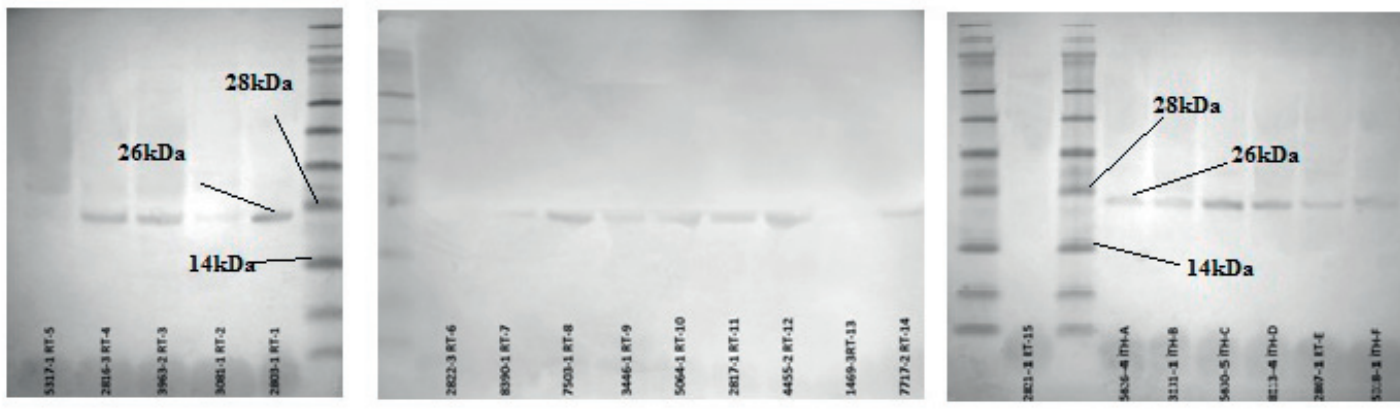

\section{B-Actin (internal control)}
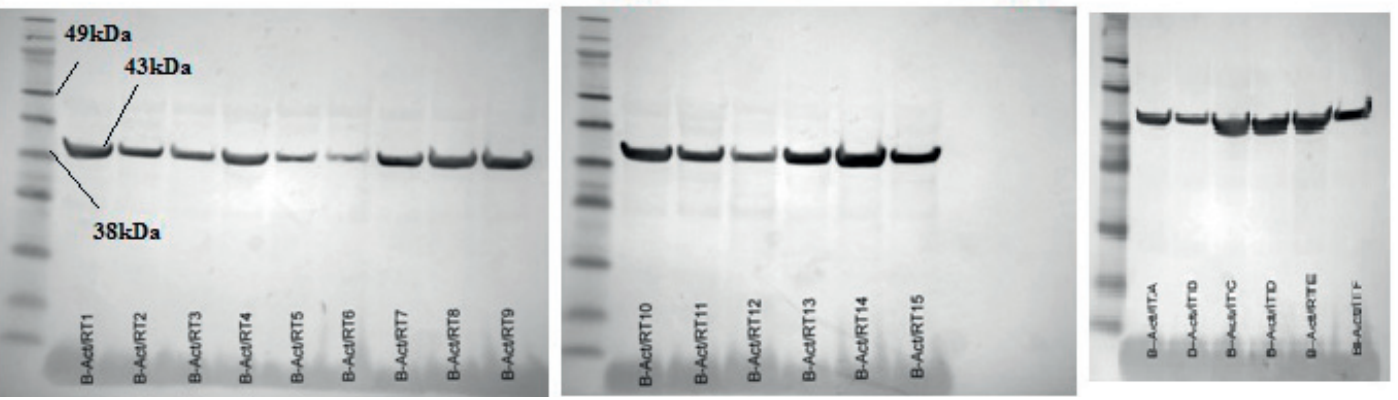

Fig. 4. Immunodetection of GSTA1, B-actin in recurrent tonsillitis and idiopathic tonsillar hypertrophy cytosolic fractions $(\sim 50 \mu \mathrm{g}$ protein $)$. 
intensity of the protein bands in the membranes was calculated using "Gel Logic Pro 2200" gel imaging system with "Carestream" software.

Protein expression differences of GSTA1 and GSTP1 isozymes and GST activity in patients with ITH and RT were assessed using MINITAB 14 statistical software and Mann Whitney-U tests with a $95 \%$ confidence level. The results were considered significant for $P<0.05$.

The ethical approval of the study was provided by Kirıkkale University Ethics committee with approval number 2009/005 and informed consents of both study groups were taken by the clinicians.

\section{RESULTS}

Increased GST activity was found in patients with recurrent tonsillitis (Fig. 1, 2). $\mathrm{GST}_{\mathrm{RT} / \mathrm{TH}}$ was found to be 1.03 , but the difference was not statistically different $(P=0.902)$ (Table 1).

Western blots were carried out on the 16 recurrent tonsillitis and 5 idiopathic tonsillar hypertrophy samples to assess the relative GSTP1 and GSTA1 isoenzyme content. Representative blots using polyclonal antibodies to GSTA1, GSTP1 are shown in Fig. 3, 4. In both tissue significant upregulation of GSTP1 and GSTA1 expressions were detected (Table 2, Fig. 3, 4) $(P<0.05)$. Moreover, expression differences of GSTP1 and GSTA1 isozymes in patients with ITH and RT were statistically analyzed by independent sample t-tests. The expression of GSTP1 was found to be significantly higher than GSTA1 in tissue samples $(P<0.001)$ (Table 2) (Fig. 3, 4).

\section{DISCUSSION}

Oxidation products are produced during the normal cell cycle in normal concentration but if the amount is above physiological levels, this situation is called oxidative stress. Antioxidants are capable of denaturating such oxidative products. In the condition that the products cannot be denaturated efficiently, the oxidative damage to cell products may lead to cellular injury and apoptosis. Both forms of antioxidants (enzymatic or non-enzymatic) have the ability to protect cells from oxidative stress and the produced materials. Infections are also responsible for increased free radicals levels in tissues ${ }^{11,12,15}$. In this condition, cells responsible for inflammation such as macrophages, neutrophils, eosinophils, and monocytes produce free radicals to defend against bacteria or viruses. Many studies demonstrate the increased levels of local antioxidants in humans during infection ${ }^{9,16-18}$., but some in vitro studies report decreased levels of antioxidants ${ }^{19,20}$.

Recurrent tonsillitis and idiopathic tonsillar hypertrophy are the two most common indications for tonsillectomy. Studies have shown that oxidant and antioxidants levels are increased in patients with tonsillitis before and after tonsillectomy. There are studies suggesting that the levels of Malondialdehyde (MDA), which is the antioxidant end product of lipid peroxidation, are reduced after tonsillectomy ${ }^{21}$. Cemek et al. ${ }^{22}$ explained this contradiction with the onset of diseases. They found the increase in SOD, GPx, CAT, ceruloplasmin levels in acute tonsillitis and acute otitis media in blood sera.

It has been stressed that disease progression in humans was spontaneous; so, local defence has a more crucial role than in animals. Moreover, Yilmaz et al. ${ }^{9}$ found increased SOD levels in tonsillectomized patients. Additionally, MDA levels in serum and tonsil tissues are increased in chronic tonsillitis $^{10,17}$. Besides, GSH levels were shown to be decreased before tonsillectomy and increased after surgery $^{23}$. Similarly, the levels of non-enzymatic antioxidants such as retinol, $\alpha$-tocopherol, $\beta$-carotene, lycopene, GSH, and ascorbic acid and enzymatic antioxidants such as SOD and GSH-Px have been shown to increase after tonsillectomy in patients with tonsillitis ${ }^{9,10}$. However, it has been reported that the pre-operative oxidative stress in patients with tonsillitis does not normalize after surgery compared with the controls and that oxidative stress continues in these patients ${ }^{11}$.

Kiroglu et al. ${ }^{24}$ investigated antioxidant and oxidant levels in chronic adenotonsillitis and tonsillar hypertrophy patients. This histological study found increase in MDA and CAT levels in chronic adenotonsillitis with respect to tonsillar hypertrophy cases. Most of these studies analysed blood samples which might have been affected by external factors, obfuscating the results. In our study design, we used tonsil tissue to investigate the GSH levels. One limitation in this study was the unavailability of the control tissue due to ethical limitations. So, the expressions of isozymes such as GSTP1 and GSTA1 in the tonsils were not studied. Spectrophotometrical and immunological measurements showed an increase in GST enzyme activity, which has an important role in the antioxidant defense mechanism by catalyzing the conjugation reactions with GSH in tonsillar tissues, and GSTP1 and GSTA1 isozymes that are members of this enzyme family. The fact that GSTP1 levels were significantly higher in tonsillar tissues than GSTA1 levels suggests that GSTP1 isozymes may be involved in the pathogenesis of the disease. As far as it is known, there are no publication on the detection of the levels of GST isozymes in the tissues of patients with tonsillitis. However, it has been shown that the level of GSTP1 tends to increase in neoplastic tissues compared to normal tissues in studies investigating the role of GST in cancers ${ }^{12,25}$.

\section{CONCLUSION}

Increased GST activity and GSTP1 isozyme expression were observed in patients with recurrent tonsillitis compared to idiopathic tonsillar hypertrophy patients. The role of GSTA1 and GSTP1 isozymes in the pathogenesis of tonsillitis were shown in this histologically designed study. One of the limitations of our study is the small sample size and groups due to single center design study and detailed selection criteria. We believe that elucidation of the etiology and pathogenesis of tonsillitis would be provided by conducting comparative experiments on 
the molecular pathway of lymphoma pathogenesis with larger studies involving both GSTs involved in detoxification and drug metabolism.

Author contributions: MGD, SA, SO: literature research, manuscript writing, critical reading, analyzing the data, manuscript revision; MK, OD, CY: manuscript revision, analyzing the data.

Conflict of interest statement: The authors declare no conflicts of interest regarding the publication of this article.

\section{REFERENCES}

1. Passàli D, Damiani V, Passàli GC, Passàli FM, Boccazi A, Bellusi L. Structural and immunological characteristics of chronically inflamed adenotonsillar tissue in childhood. Clin Diagn Lab Immunol 2004;11:1154-7.

2. Brandtzaeg P. Immunology of tonsils and adenoids: everything the ENT surgeon needs to know. Int J Pediatr Otorhinolaryngol 2003;67:69-76.

3. Surjan JR, Brandtzaeg P, Berdal P. Immunoglobulin systems in human tonsils II. Patients with chronic tonsillitis or tonsillar hyperplasia: quantification of Ig-producing cells, tonsillar morphometry and serum Ig concentrations. Clin Exp Immunol 1978;31:382-90.

4. Shukla GK, Mahajan A, Pandey S, Gujrati VR, Vrat S, Mishra SC, Shanker K. A study of free radicals and scavenging enzyme in tonsillitis. Boll Chim Farm 1996;135:653-5.

5. Doğru H, Delibas, N, Döner F, Tüz M, Uygur K. Free radical damage in nasal polyp tissue. Otolaryngol Head Neck Surg 2001;124:570-2.

6. Takoudes TG, Haddad J. Lipid peroxides in middle ear fluid after acute otitis media in guinea pigs. Ann Otol Rhinol 1999;108:564-8.

7. Kaygusuz I, Oztürk A, Ustündağ B, Yalcın S. Role of free oxygen radicals in noise-related hearing impairment. Hear Res 2001;162:43-7.

8. Klusek J, Głuszek S, Klusek J. GST gene polymorphisms and the risk of colorectal cancer development. Contemp Oncol 2014;18:219-21.

9. Yilmaz T, Kocan EG, Besler HT. The role of oxidants and antioxidants in chronic tonsillitis and adenoid hypertrophy in children. Int J Pediatr Otorhinolaryngol 2004;68(8):1053-8.

10. Doğruer ZN, Unal M, Eskandari G, Pata YS, Akbaş Y, CevikT, Cimen MY Malondialdehyde and antioxidant enzymes in children with obstructive adenotonsillar hypertrophy. Clin Biochem 2004;37(8):718-21.
11. Cvetković T, Vlahović $P$, Todorović M, Stanković M. Investigation of oxidative stress in patients with chronic tonsillitis. Auris Nasus Larynx 2009;36(3):340-4. doi: 10.1016/j.anl.2008.10.004

12. Simsek GG, Oguztuzun S, Bozer B, Kılıc M, Kocdogan AK, Kaygın $\mathrm{P}$, Gurbuz N, Bulus H. Expressions of CYP and GST Isoenzymes in Human Gastric Tumor and Non-Tumor Tissues. International Journal of Hematology and Oncology 2018;28(1):36-44.

13. Randel A. AAO-HNS Guidelines For Tonsillectomy In Children And Adolescents. Am Fam Physician 2011:84:566-73.

14. Lowry $\mathrm{OH}$, Rosebrough NJ, Farr AL. Protein measurement with the folin phenol reagent, J Biol Chem 1951;248:265-75.

15. Oguztuzun S, Abu-Hıjleh A, Coban T, Bulbul D, Kılıc M, Iscan M. GST isoenzymes in matched normal and neoplastic breast tissue. Neoplasma 2011;58(4):304-10.

16. Aktan B, Taysi S, Gumustekin K, Bakan N, Sutbeyaz Y. Evaluation of oxidative stress in erythrocytes of guinea pigs with experimental otitis media and effusion, Ann Clin Lab Sci 2003;33(2):232-6.

17. Shukla GK, Garg A, Bhatia N, Pandey S, Kaur G, Shukla RN, Shanker $\mathrm{K}$. Significance of free radicals in chronic tonsillitis, Boll Chim Farm 2000;139(2):103-5.

18. Shigemi H, Egashira T, Kurono Y, Mogi G. Role of superoxide dismutase in otitis media with effusion, Ann Otol Rhinol Laryngol 1998; 107(4):327-31

19. Parks RR, Huang CC, Haddad J Jr. Superoxide dismutase in an animal model of otitis media, Eur Arch Otorhinolaryngol 1995;252(3):153-8.

20. Parks RR, Huang CC, Haddad J Jr. Middle ear catalase distribution in an animal model of otitis media, Eur Arch Otorhinolaryngol 1996;253(8):445-59.

21. Kaygusuz I, Ilhan N, Karlidag T, Keles E, Yalcin S, Cetiner H. Free radicals and scavenging enzymes in chronic tonsillitis Otolaryngol Head Neck Surg 2003;129(3):265-8.

22. Cemek M, Caksen H, Cemek F, Bayiroglu F, Dede S, Dulger H, Ustun R Investigation of antioxidant status in children with acute otitis media and tonsillitis, Int J Pediatr Otorhinolaryngol 2004;68(11):1381-5.

23. Garcia Calleio FJ, Orts Alborch MH, Velert Vila MM, Fernandez Julian EN, Blay Galaud L, Marco Algarra J. Oxidative profile of tonsil infection. Study of antioxidant enzymes in tonsil and blood Acta otorrinolaringologica espanola 2002;53(6):398-404.

24. Kiroglu AF, Noyan T, Oger M, Kara T. Oxidants and antioxidants in pathogenesis of chronic adenotonsillitis. Int J Pediatr Otolaryngol 2006;70:35-38.

25. Bulus H, Oguztuzun S, Simsek GG, Kilic M, Ada AO, Göl S, Kocdogan AK, Kaygın P, Bozer B, Iscan M. Expression of CYP and GST in human normal and colon tumor tissues. Biotech Histochem 2018;9:1-9. doi: 10.1080/10520295.2018.1493220. [Epub ahead of print] 